Minireview

\title{
Role of bicarbonate at the acceptor side of Photosystem II
}

\author{
Jack J. S. van Rensen \\ Graduate School of Experimental Plant Sciences, Wageningen University, Laboratory of Plant Physiology, \\ Arboretumlaan 4, 6703 BD Wageningen, The Netherlands (e-mail: Jack.VanRensen@PPH.dpw.wau.nl; fax: \\ $+31-317-484740$ )
}

Received 5 February 2001; accepted in revised form 24 October 2001

Key words: bicarbonate, chlorophyll fluorescence, Bruce Diner, electron flow, Norman Good, Govindjee, Photosystem II, Jack van Rensen, Otto Warburg, Thomas Wydrzynski

\begin{abstract}
Besides being the substrate for the carboxylation reaction of photosynthesis, $\mathrm{CO}_{2}$ (bicarbonate) is required for the activity of Photosystem II (water plastoquinone oxido-reductase). It plays a role on the electron donor side as well as the electron acceptor side. In this contribution, attention will mostly be focused on the history of research into the effects of bicarbonate on electron flow reactions on the acceptor side. Donor side reactions are discussed in this issue by Alan Stemler.
\end{abstract}

Abbreviations: Chl - chlorophyll; DCMU (diuron) - 3-(3,4-dichlorophenyl)-1,1-dimethylurea; PS II - Photosystem II; PQ - plastoquinone; $\mathrm{Q}_{\mathrm{A}}$ - primary quinone electron acceptor of PS II; $\mathrm{Q}_{\mathrm{B}}$ - secondary quinone electron acceptor of PS II

\section{Introduction}

In one of the earliest reviews about the effects of bicarbonate in Photosystem II (Govindjee and Jack van Rensen 1978), it was recalled that Jean Senebier (1782) was the earliest to note that the production of 'dephlogisticated air' (that is, oxygen) by plants requires the presence of 'fixed air' (carbon dioxide). Today, the role of carbon dioxide in photosynthesis is well understood; carbon dioxide is the substrate for the enzymatic reaction involved in this gas's reduction to carbohydrate. For a long time $\mathrm{CO}_{2}$ was not thought to play a role in the light-based reactions of the photosynthetic process. A convenient example of such reactions is the Hill reaction (Robin Hill 1937; see David Walker, this issue), which allows a study to be made of oxygen evolution resulting from isolated broken chloroplasts illuminated in the presence of an artificial electron acceptor, such as ferricyanide or methyl viologen. The late Otto Warburg and Günter Krippahl (1958) discovered that this Hill reaction requires the presence of $\mathrm{CO}_{2}$; in grana from kohlrabi leaves and using quinone or ferricyanide as an electron acceptor oxygen was evolved at a higher rate when the argon gas in the vessel contained $1.4 \% \mathrm{CO}_{2}$ (Figure 1; photographs of Otto Warburg appear elsewhere in this special issue in papers by Andrew A. Benson, Peter Homann, and Alan Stemler). This phenomenon was confirmed in the 1960 s by many workers, e.g., the late Norman Good, the late Seikichi Izawa and the late Birgit Vennesland (for references, see the review by Danny Blubaugh and Govindjee 1988). However, there was little agreement as to the conditions necessary for the dependence of the Hill reaction on $\mathrm{CO}_{2}$ and on the significance of such dependence. Norman Good (1963) studied the conditions under which a dependence of the Hill reaction on the presence of bicarbonate could be observed. Because he found that dependence on bicarbonate was correlated with the presence of other small anions during the depletion period, Good concluded that bicarbonate is the important species, not $\mathrm{CO}_{2}$. This conclusion was later confirmed by Blubaugh and Govindjee (1986) by taking advantage of the $\mathrm{pH}$ dependence of the equilibrium 


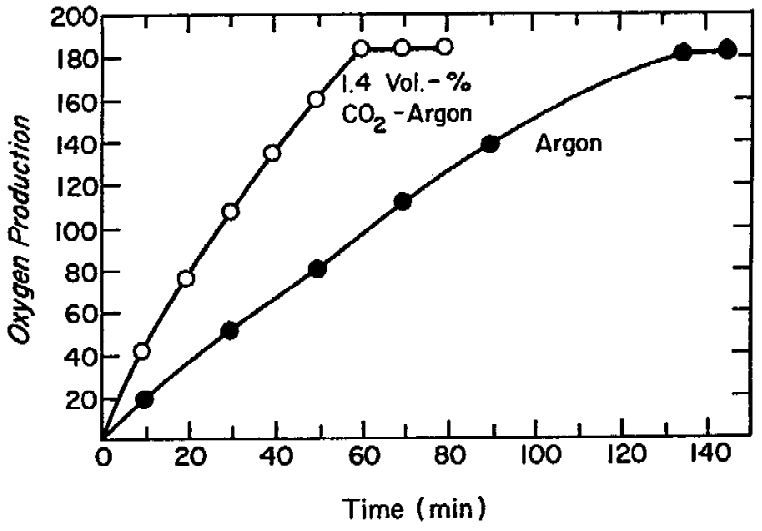

Figure 1. Experiments with grana suspended in $0.1 \% \mathrm{KCl}(3 \mathrm{ml}$ vessel). Electron acceptor, $2.1 \mathrm{mg}$ quinone; gas phase, Argon or Argon $+1.4 \% \mathrm{CO}_{2}$ by volume. (after Warburg and Krippahl 1958). This experiment shows that $\mathrm{CO}_{2}$ enhances the rate of the Hill reaction.

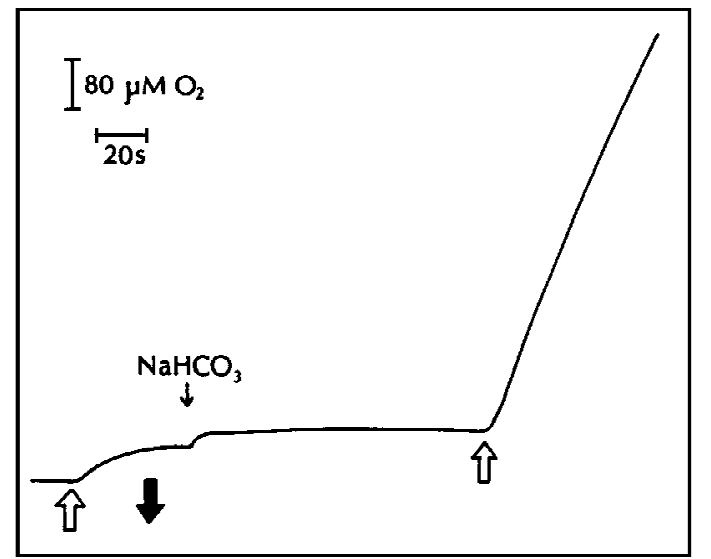

Figure 2. A typical example of the bicarbonate effect on a Hill reaction. Isolated chloroplasts (thylakoid membranes) were depleted of $\mathrm{CO}_{2}$ in a medium at $\mathrm{pH} 5.8$ in the presence of $25 \mathrm{mM}$ formate while nitrogen gas was flushed over the suspension during $30 \mathrm{~min}$. The recording of oxygen evolution was measured at $\mathrm{pH} 6.5$ and is illustrated before and after the addition of $10 \mathrm{mM} \mathrm{NaHCO}_{3}$. Arrow pointing upwards, light on; arrow downwards, light off.

ratio of $\left[\mathrm{CO}_{2}\right]$ to $\left[\mathrm{HCO}_{3}{ }^{-}\right]$to effectively hold one concentration constant while varying the other. The restoration of the Hill reaction was shown to be dependent only on the bicarbonate concentration over the $\mathrm{pH}$ range studied. $\mathrm{CO}_{2}$ is the diffusing species and bicarbonate the active species.

Alan Stemler and Govindjee (1973) developed a reliable method to show the bicarbonate effect: they depleted isolated chloroplasts in a medium containing a high anion concentration at a $\mathrm{pH}$ below 6.0 and flushed nitrogen gas over the suspension in the dark. Because the $\mathrm{pK}$ of $\mathrm{H}_{2} \mathrm{O}+\mathrm{CO}_{2} \leftrightarrow \mathrm{H}_{2} \mathrm{CO}_{3}$ is 6.37 , at low $\mathrm{pH}$ the equilibrium favors $\mathrm{CO}_{2}$, which disappears by flushing with nitrogen gas. After depletion, the chloroplasts were transferred to a $\mathrm{pH}$ of 6.5 and the Hill reaction was measured after addition of an electron acceptor. The Hill reaction rate was low, but after addition of bicarbonate the rate was increased by several manifold. A typical example of such an experiment is illustrated in Figure 2 (J.J.S. van Rensen, unpublished).

Otto Warburg (1964) had considered the effect of bicarbonate on the Hill reaction as proof of his theory that oxygen arises from the splitting of $\mathrm{CO}_{2}$ and not $\mathrm{H}_{2} \mathrm{O}$. One of the first to question the notion of direct splitting of water was Helmut Metzner (Metzner and Fischer 1969). Stemler (1980, 1982) has also always advocated a role of $\mathrm{CO}_{2}$ in the process of water splitting in addition to the acceptor side effects. New results from the group led by Vyacheslav Klimov (see review by Klimov and Baranov 2001) may show that Stemler's views are correct in the end (Stemler, this issue).

Nevertheless, in 1975 Thomas Wydrzynski and Govindjee found that bicarbonate had an effect on the electron acceptor side of PS II. With this discovery, a new era of work began. The remaining history presented in this paper will concentrate on the research into this phenomenon. Figure 3 shows Govindjee with several of his former doctoral and postdoctoral associates, including the author, Stemler and Wydrzynski, (Photo, October, 1999).

\section{Early evidence for the effect of bicarbonate at the acceptor side of Photosystem II}

The first indication for an effect of bicarbonate on the reducing side of Photosystem II was observed by Wydrzynski and Govindjee (1975), who measured Chl $a$ fluorescence induction kinetics in chloroplasts after $\mathrm{CO}_{2}$ depletion. The variable $\mathrm{Chl} a$ fluorescence monitors the redox state of $\mathrm{Q}_{\mathrm{A}}$; $\mathrm{Q}_{\mathrm{A}}$ is a quencher of fluorescence, whereas $\mathrm{Q}_{\mathrm{A}}^{-}$is not (Duysens and Sweers 1963). Therefore, a rapid accumulation of $\mathrm{Q}_{\mathrm{A}}{ }^{-}$due to an inhibition of electron transport beyond $\mathrm{Q}_{\mathrm{A}}$ is easily detected by fluorescence induction measurements. $\mathrm{CO}_{2}$ depletion causes a fast increase in the variable fluorescence yield, similar but not identical to that observed in normal chloroplasts in the presence of the herbicide DCMU (Wydrzynski and Govindjee 1975). DCMU is known to block the reoxidation of $\mathrm{Q}_{\mathrm{A}}{ }^{-}$by the secondary quinone acceptor $\mathrm{Q}_{\mathrm{B}}$ (Figure 4). 
(a)

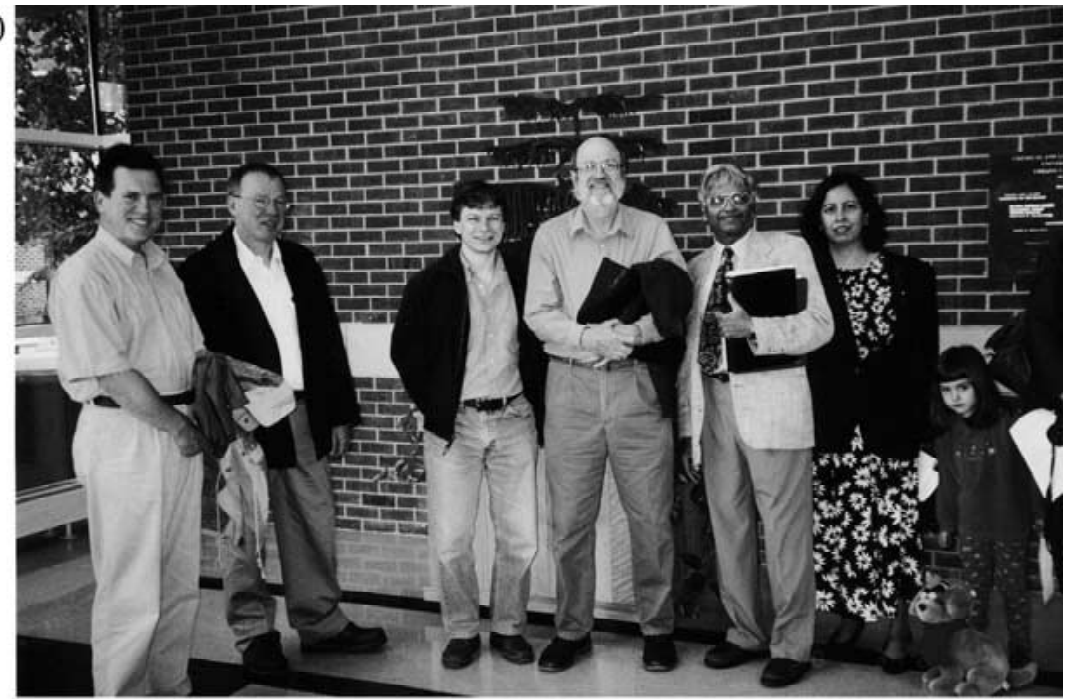

(b)

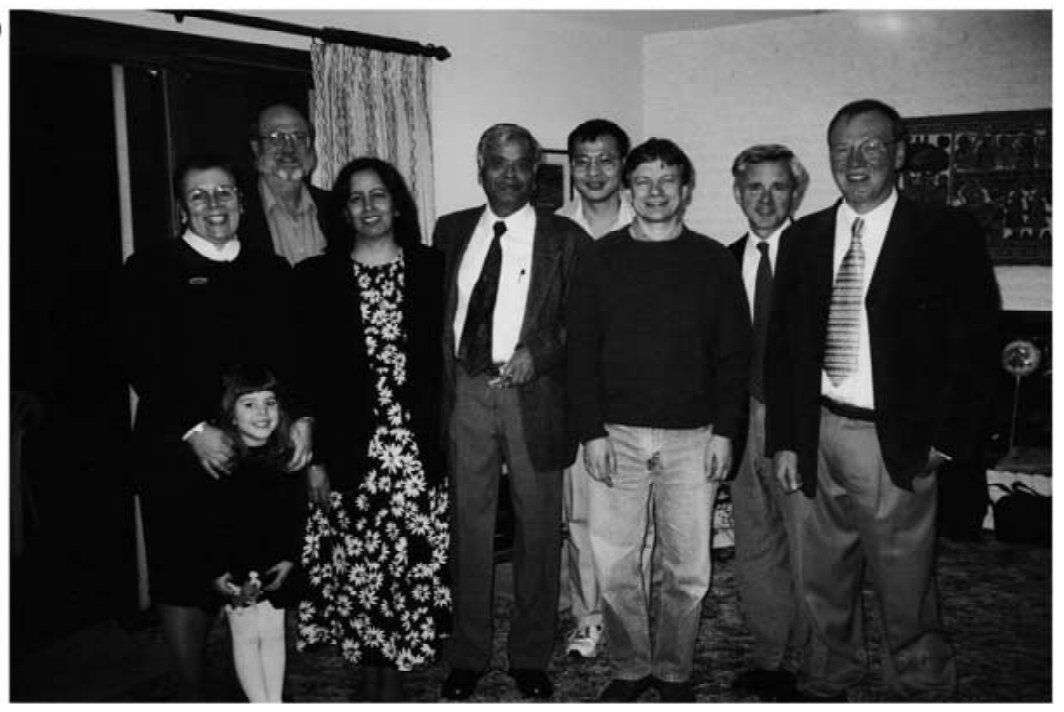

Figure 3. Two photographs of Govindjee's research group gathered at his retirement in October, 1999, at Urbana, Illinois, USA. From left to right in (a): Jack van Rensen, Thomas Wydrzynski, Julian Eaton-Rye, Alan Stemler, Govindjee, and Rita Khanna. Photograph by Jin Xiong. (b) Barbara Zilinskas (who had worked on the partial reactions of photosynthesis, and antibodies against PS II in the 1970s), Alan Stemler, Rita Khanna, Govindjee, Jin Xiong, Julian Eaton-Rye, Paul Jursinic, and Thomas Wydrzynski. The little girl (four years old) in both the pictures is Govindjee's granddaughter Sunita Christiansen. Photograph taken by Rajni Govindjee. Others who had worked with Govindjee, in his lab, at Urbana, on the bicarbonate effect in PS II, but are missing from the photographs, are Danny Blubaugh, Jinchiang Cao, G. Sarojini, Wim Vermaas, and Chunhe $\mathrm{Xu}$.

During a sabbatical in 1976 with Louis Duysens' research group in Leiden, Govindjee studied the DCMU-induced chlorophyll $a$ fluorescence increase as a function of the number of pre-illuminating flashes and found that the binary oscillations, normally observed in $\mathrm{Q}_{\mathrm{A}}{ }^{-}$reoxidation, were absent in $\mathrm{CO}_{2}$ depleted chloroplasts (Govindjee et al. 1976). The measurement of chlorophyll $a$ fluorescence yield after pre-illuminating flashes became an important tool to study the bicarbonate effect, especially in Govindjee's group. The decay of the chlorophyll $a$ fluorescence yield after a saturating flash monitors the reoxidation of $\mathrm{Q}_{\mathrm{A}}{ }^{-}$. Detailed information about the effect of $\mathrm{CO}_{2}$ depletion was obtained by measuring the decay of the chlorophyll $a$ fluorescence yield after various numbers 
of short saturating flashes. With this technique, the following events are monitored.

After an odd number of flashes:

$$
\mathrm{Q}_{\mathrm{A}} \mathrm{Q}_{\mathrm{B}} \stackrel{\mathrm{h} \nu}{\rightarrow} \mathrm{Q}_{\mathrm{A}}{ }^{-} \mathrm{Q}_{\mathrm{B}} \rightarrow \mathrm{Q}_{\mathrm{A}} \mathrm{Q}_{\mathrm{B}}{ }^{-}
$$

After an even number of flashes:

$$
\mathrm{Q}_{\mathrm{A}} \mathrm{Q}_{\mathrm{B}} \stackrel{-\mathrm{h} v}{\rightarrow} \mathrm{Q}_{\mathrm{A}}^{-} \mathrm{Q}_{\mathrm{B}}^{-} \rightarrow \mathrm{Q}_{\mathrm{A}} \mathrm{Q}^{2-}
$$

$\mathrm{QB}^{2-}$ becomes protonated and exchanges with the PQ pool: $\mathrm{Q}_{\mathrm{A}} \mathrm{Q}_{\mathrm{B}}{ }^{2-}+2 \mathrm{H}^{+}+\mathrm{PQ} \rightarrow \mathrm{Q}_{\mathrm{A}} \mathrm{Q}_{\mathrm{B}}+\mathrm{PQH}_{2}$

Govindjee et al. (1976) found no differences in the fluorescence yield measured $160 \mathrm{~ms}$ after the last of a various number of flashes in control and in $\mathrm{CO}_{2-}$ depleted chloroplasts to which bicarbonate was added. In $\mathrm{CO}_{2}$-depleted chloroplasts, however, they found little effect on the fluorescence intensity measured 160 ms after one or two flashes, but a much higher fluorescence after three or more flashes. It was reported by Paul Jursinic and Alan Stemler (1982) that the decay of fluorescence after one or many flashes was slower in depleted samples in both the $50 \mu$ s to $10 \mathrm{~ms}$ range and the $10 \mathrm{~ms}$ to $5 \mathrm{~s}$ time range. In $\mathrm{CO}_{2}$-depleted samples, the half-time of the decay after one flash was in the short-term about $6 \mathrm{~ms}$, and in the long-term about 1-2 s (Jursinic is shown in Figure 3b) Howard Robinson et al. (1984) measured fluorescence decay in a time range up to $10 \mathrm{~ms}$ and showed that the half-time of the $\mathrm{Q}_{\mathrm{A}}{ }^{-}$-decay after one flash was $1.2 \mathrm{~ms}$ in $\mathrm{CO}_{2}$-depleted chloroplasts and $230 \mu \mathrm{s}$ in control chloroplasts: a fivefold difference. After three or more flashes, half-times were $13 \mathrm{~ms}$ for bicarbonate-depleted and $360 \mu$ s for the control: a 36-fold slower decay in bicarbonatedepleted samples. Although the absolute values of the rates of $\mathrm{Q}_{\mathrm{A}}{ }^{-}$-decay in this type of experiment depend on the conditions of the experiment, it was clear that there is a smaller inhibition of $\mathrm{CO}_{2}$ depletion on the $\mathrm{Q}_{\mathrm{A}}{ }^{-}$reoxidation by $\mathrm{Q}_{\mathrm{B}}$ or by $\mathrm{Q}_{\mathrm{B}}{ }^{-}$but a much larger inhibition of the protonation of $\mathrm{Q}_{\mathrm{B}}{ }^{2-}$ and/or exchange of $\mathrm{Q}_{\mathrm{B}} \mathrm{H}_{2}$ with the plastoquinone pool. In $\mathrm{CO}_{2}$-depleted chloroplasts three electrons can be stored so that $\mathrm{Q}_{\mathrm{A}}{ }^{-} \mathrm{Q}_{\mathrm{B}}{ }^{2-}$ is produced.

\section{Binding sites of bicarbonate}

The site of inhibition by $\mathrm{CO}_{2}$-depletion was also determined by studying its effect on various parts of the electron transport chain (Rita Khanna et al. 1977; Khanna can be seen in Figures $3 a$ and b). There was no effect of $\mathrm{CO}_{2}$ depletion on electron transport from reduced diaminodurene to methyl viologen, indicating the absence of an effect on PhotosystemI-dependent electron transport. A large bicarbonate effect was demonstrated on the electron flow from water to oxidized diaminodurene in the presence of dibromothymoquinone (DBMIB), indicating an effect before the plastoquinone pool. Since the electron flow from water to silicomolybdate in the presence of DCMU was not affected by $\mathrm{CO}_{2}$ depletion, it was concluded that the bicarbonate effect was located between $\mathrm{Q}_{\mathrm{A}}$ and the PQ pool. It was reported, however, that silicomolybdate-supported oxygen evolution in the presence of DCMU was inhibited by formate and bicarbonate (Fred Crane and Rita Barr 1977; Jursinic and Stemler 1986). From the absence of a bicarbonate effect on electron transport in trypsintreated chloroplasts, in which ferricyanide accepts electrons directly at the $\mathrm{Q}_{\mathrm{A}}$ site (Jack van Rensen and Wim Vermaas 1981), it was again concluded that the location of the bicarbonate effect was between $\mathrm{Q}_{\mathrm{A}}$ and the PQ pool.

The localization of the bicarbonate effect between $\mathrm{Q}_{\mathrm{A}}$ and the plastoquinone pool was further concluded from the interaction of bicarbonate (or formate) with Photosystem II inhibiting herbicides. Van Rensen and coworkers (van Rensen and Vermaas 1981; Khanna et al. 1981; Snel and van Rensen 1983) studied the interaction of bicarbonate and herbicides through their effects on electron transport in isolated chloroplasts. By adding various concentrations of bicarbonate to $\mathrm{CO}_{2}$-depleted chloroplasts, various rates of restoration of the Hill reaction were obtained. It was demonstrated that the effect of bicarbonate on thylakoid membranes shows Michaelis-Menten kinetics and that the thylakoid system can be treated like an enzyme versus bicarbonate, the substrate. From double reciprocal plots of the rate of the Hill reaction as a function of the bicarbonate concentration, the apparent dissociation constant $\left(K_{\mathrm{d}}\right)$ of the thylakoid-bicarbonate complex could be calculated. When $100 \mathrm{mM}$ formate is present in the reaction medium, the apparent $K_{\mathrm{d}}$ appears to be about $1 \mathrm{mM}$ bicarbonate, the same value was reported by Stemler and Judith Murphy (1983). The $K_{\mathrm{d}}$ for bicarbonate depends on the presence of both formate and of herbicides: in the presence of low concentrations of formate the apparent $K_{\mathrm{d}}$ decreases, approaching $80 \mu \mathrm{M} \mathrm{NaHCO} 3$ in the absence of formate, and in the presence of urea, triazine or phenol-type herbicides, the $K_{\mathrm{d}}$ for bicarbonate increases by at least twofold (Stemler and Murphy 1983; Snel and van 
a

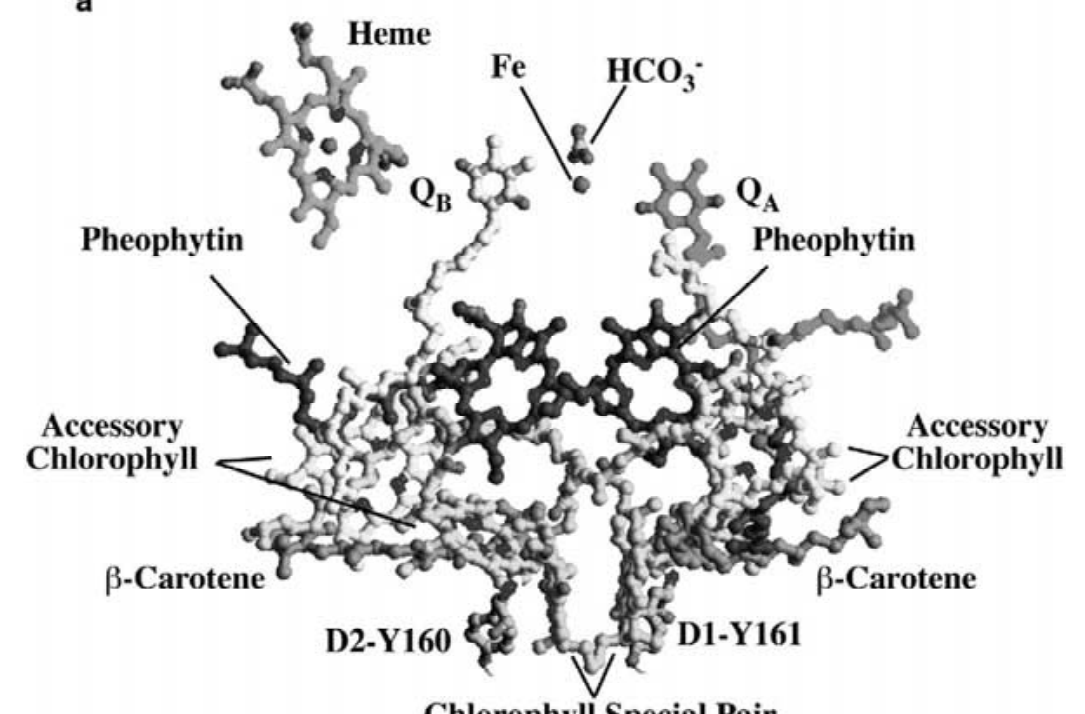

Chlorophyll Special Pair

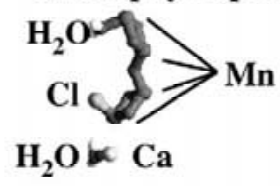

b

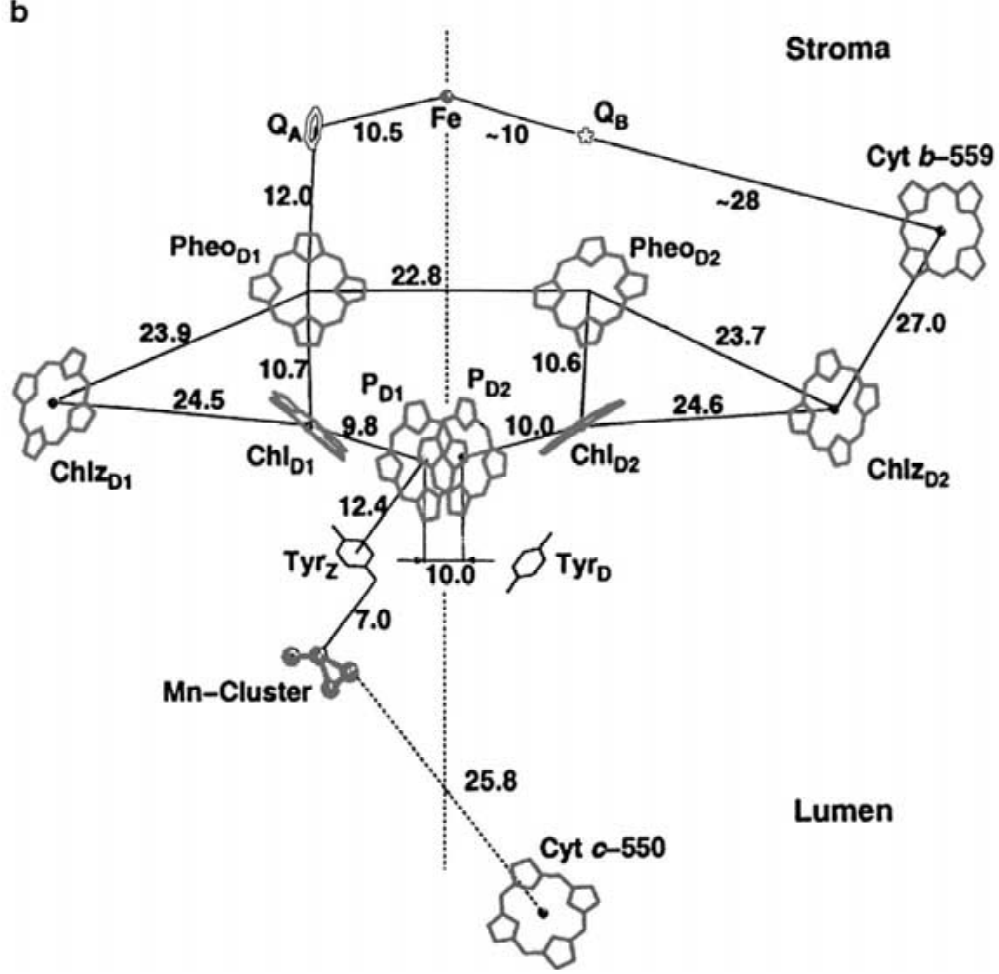

Figure 4. Top: the modeled cofactors in the PS II reaction center (from Xiong et al. 1998b; with kind permission from the authors). Bottom: chromophores and distances between them (from Zouni et al. 2001; with permission from H.T. Witt). Courtesy of Govindjee and of Jin Xiong. For a color version of this figure, see section in the front of the issue. 
Rensen 1984). This means that these herbicides decrease the apparent affinity of the thylakoid membrane for bicarbonate. Also, it was observed that chloroplasts isolated from atrazine-resistant plants have a lower affinity for bicarbonate than wild-type ones (Khanna et al. 1981). These resistant plants have an alteration in the amino acid composition of the D1 protein: serine 264 is exchanged for glycine.

The above arguments led strongly to the suggestion that the binding sites of bicarbonate are located on the D1 protein of Photosystem II. Hartmut Michel and Johann Deisenhofer (1988) compared the primary structure of the L and M polypeptides of the bacterial reaction centers with the D1 and D2 polypeptides of Photosystem II and suggested that glutamate in bacteria is replaced by bicarbonate in PS II as a ligand to the nonheme iron. Interestingly, it was demonstrated by R. Shopes et al. (1989) that the bicarbonate effect is absent in anoxygenic photosynthetic bacteria. Wim Vermaas and William (Bill) Rutherford (1984) demonstrated that formate addition to thylakoids increases the amplitude of the $g=1.82 \mathrm{EPR}$ signal of $\mathrm{Q}_{\mathrm{A}}{ }^{-} \mathrm{Fe}^{2+}$ 10-fold (see also Jonathan Nugent et al. 1988). A formate/bicarbonate effect was established clearly by measurements of EPR spectra of the $\mathrm{Q}_{\mathrm{A}}{ }^{-} \mathrm{Fe}-\mathrm{Q}_{\mathrm{B}}$ complex with and without bicarbonate (Simon Bowden et al. 1991). The Mössbauer spectrum of Fe was affected significantly by formate and was returned to its original on re-addition of bicarbonate, indicating that $\mathrm{Fe}$ is a key element in the binding of formate that is displaced by bicarbonate (Bruce Diner and Vasili Petrouleas 1987; Semin et al. 1990). A Fourier transform infrared (FTIR) difference spectroscopy study using ${ }^{13} \mathrm{C}$-labeled bicarbonate established that bicarbonate is a bidentate ligand of the nonheme iron (Hienerwadel and Catherine Berthomieu 1995). Examining the effects of a number of carboxylate anions on the EPR signals associated with the non-heme iron, Petrouleas et al. (1994) observed that glycolate, glyoxylate, and oxalate compete with NO, formate and bicarbonate for binding to the nonheme iron. Further work, mainly by Govindjee's group, led to the conclusion that there are two binding sites (Blubaugh and Govindjee 1988) for bicarbonate in the D1 protein of PS II: one on the nonheme iron and the other near arginine 257 (Xiong et al. 1996, 1998a; van Rensen et al. 1999; Xiong is visible in Figure 3b). One of these locations is illustrated in Figure 4 (top).

\section{Function of bicarbonate on the acceptor side of Photosystem II}

The functions of bicarbonate in PS II are not yet clear. There have been early suggestions that bicarbonate and formate may interfere with protonation reactions near $\mathrm{Q}_{\mathrm{B}}$ (see a review by Govindjee and van Rensen 1993). It is possible that $\mathrm{H}_{2} \mathrm{CO}_{3}$ is involved in the protonation of $\mathrm{Q}_{\mathrm{B}}{ }^{2-}$ or its proteinaceous environment, since the $\mathrm{pK}_{a}$ of $\left(\mathrm{CO}_{2}+\mathrm{H}_{2} \mathrm{O}\right)$ is 6.37 at $25{ }^{\circ} \mathrm{C}$. $\mathrm{CO}_{2} / \mathrm{HCO}_{3}{ }^{-} / \mathrm{CO}_{3}{ }^{2-}$ could serve as a proton shuttle between $\mathrm{Q}_{\mathrm{B}}$ and the external aqueous phase. Formate is not able to function in such a way, because the $\mathrm{pK}_{a}$ of formate is 3.8. Evidence for such a function was obtained by van Rensen et al. (1988), Julian Eaton-Rye and Govindjee (1988) and Chunhe Xu et al. (1991). (Eaton-Rye is to be seen in Figures $3 \mathrm{a}$ and b.)

Because bicarbonate is liganded to the nonheme iron, an additional role of bicarbonate may be to stabilize the $\mathrm{Q}_{\mathrm{A}}-\mathrm{Fe}-\mathrm{Q}_{\mathrm{B}}$ structure. Upon the removal of bicarbonate, the distance between $\mathrm{Q}_{\mathrm{A}}$ and $\mathrm{Q}_{\mathrm{B}}$ may be altered, slowing down the rate of electron flow between these two quinone acceptors (van Rensen et al. 1999). Such an influence of bicarbonate does not explain, however, why the decay of the fluorescence yield after three or more flashes is much more strongly affected than after the first flash.

Current knowledge of the bicarbonate effect is almost exclusively based on experiments carried out with isolated thylakoid membranes. The observation of a bicarbonate effect on Photosystem II in vivo is difficult to distinguish from the obvious requirement for $\mathrm{CO}_{2}$ in the Calvin-Benson cycle. There is only a small number of reports about an effect of bicarbonate on PS II in vivo. A few observations on in vivo effects on Photosystem II are given by Gyözö Garab et al. (1983), Dierk Mende and Wolfgang Wiessner (1985), and Fatma El-Shintinaway and Govindjee (1990).

Under conditions in which photosynthesis can proceed well, enough bicarbonate is probably bound to PS II in order for PS II to function normally. However, under stress conditions (e.g., drought, high light intensity, high temperature) the stomata may close, which would lead to a decrease in internal $\mathrm{CO}_{2}$ concentration that may limit the activity of PS II. It has been suggested several times that bicarbonate may be involved in the process of photoinhibition (for references, see van Rensen et al. 1999). 


\section{Concluding remarks}

At the evolutionary time that a PS-II-type reaction center incorporated a water-oxidizing machinery using water as a source for electrons, the atmosphere contained a high concentration of $\mathrm{CO}_{2}$. It is conceivable that with abundant amounts of carbon dioxide, $\mathrm{CO}_{2}$ was used in some way to make PS II functional. It will be challenging to search for those functions in the future. The resolution of the structure of the PS II reaction center (see Zouni et al. 2001) will be a great help in the design of new experiments, both at the acceptor as well as at the donor side of PS II. We anxiously await the final verdict on the recent suggestions of V. Klimov, Charles Dismukes, and others (see e.g. Dismukes et al. 2001) that bicarbonate may indeed be involved on the donor side of PS II. This is a new beginning to indeed test the idea of the role of bicarbonate on the donor side of PS II (also see A.J. Stemler, this issue), in addition to the established role of bicarbonate on the acceptor side of PS II discussed here.

\section{Acknowledgments}

I am thankful to Govindjee, Rita Khanna, Jan Snel, and Wim Vermaas for their participation in the bicarbonate effect work cited here. I am grateful to Kluwer Academic Publishers and Editor Govindjee for publishing Figure 4 in color.

\section{References}

Blubaugh DJ and Govindjee (1986) Bicarbonate, not $\mathrm{CO}_{2}$ is the species required for the stimulation of Photosystem II electron transport. Biochim Biophys Acta 848: 147-152

Blubaugh DJ and Govindjee (1988) The molecular mechanism of the bicarbonate effect at the plastoquinone reductase site of photosynthesis. Photosynth Res 19: 85-128

Bowden SJ, Hallahan BJ, Ruffle SV, Evans MCW and Nugent JHA (1991) Preparation and characterization of Photosystem II core particles with and without bound bicarbonate. Biochim Biophys Acta 1060: 89-96

Crane FL and Barr R (1977) Stimulation of photosythesis by carbonyl compounds and chelators. Biochem Biophys Res Commun 74: $1362-1368$

Diner BA and Petrouleas V (1987) $\mathrm{Q}_{400}$, the non-heme iron of the Photosystem II iron-quinone complex. A spectroscopic probe of quinone and inhibitor binding to the reaction center. Biochim Biophys Acta 895: 107-125

Dismukes GC, Klimov VV, Baranov SV, Kozlov Yu N, DasGupta J and Tyryshkin A (2001) The origin of atmospheric oxygen on earth: the innovation of oxygenic photosynthesis. Proc Natl Acad Sci USA 98: 2170-2175
Duysens LNM and Sweers HE (1963) Mechanisms of the two photochemical reactions in algae as studied by means of fluorescence. In: Japanese Society of Plant Physiologists (ed) Studies on Microalgae and Photosynthetic Bacteria, pp 353-372. University of Tokyo Press, Tokyo

Eaton-Rye JJ and Govindjee (1988) Electron transfer through the quinone acceptor complex of Photosystem II after one or two actinic flashes in bicarbonate-depleted spinach thylakoid membranes. Biochim Biophys Acta 935: 248-257

El-Shintinawy F and Govindjee (1990) Bicarbonate effects in leaf discs from spinach. Photosynth Res 24: 189-200

Garab G, Sanchez Burgos AA, Zimányi L and Faludi-Dániel A (1983) Effect of $\mathrm{CO}_{2}$ on the energization of thylakoids in leaves of higher plants. FEBS Lett 154: 323-327

Good NE (1963) Carbon dioxide and the Hill reaction. Plant Physiol 38: 298-304

Govindjee and van Rensen JJS (1978) Bicarbonate effects on the electron flow in isolated broken chloroplasts. Biochim Biophys Acta 505: 183-213

Govindjee and van Rensen JJS (1993) Photosystem II reaction center and bicarbonate. In: Deisenhofer J and Norris JR (eds) The Photosynthetic Reaction Center, Vol 1, pp 357-388. Academic Press, New York

Govindjee, Pulles MJP, Govindjee R, van Gorkom HJ and Duysens LNM (1976) Inhibition of the reoxidation of the secondary electron acceptor of Photosystem II by bicarbonate depletion. Biochim Biophys Acta 449: 602-605

Hienerwadel R and Berthomieu C (1995) Bicarbonate binding to the non-heme iron of Photosystem II investigated by Fourier transform infrared difference spectroscopy and ${ }^{13} \mathrm{C}$-labeled bicarbonate. Biochemistry 34: 16288-16297

Hill R (1937) Oxygen evolved by isolated chloroplasts. Nature 139: 881-882

Jursinic P and Stemler A (1982) A seconds range component of the reoxidation of the primary Photosystem II acceptor, Q. Effects of bicarbonate depletion in chloroplasts. Biochim Biophys Acta 681: 419-428

Jursinic P and Stemler A (1986) Correlation between the binding of formate and decreased rates of charge transfer through the Photosystem II quinones. Photochem Photobiol 43: 205-212

Khanna R, Govindjee and Wydrzynski T (1977) Site of bicarbonate effect in Hill reaction. Evidence from the use of artificial electron acceptors and donors. Biochim Biophys Acta 462: 208-214

Khanna R, Pfister K, Keresztes A, van Rensen JJS and Govindjee (1981) Evidence for a close spatial location of the binding sites for $\mathrm{CO}_{2}$ and for Photosystem II inhibitors. Biochim Biophys Acta 634: 195-116

Klimov VV and Baranov SV (2001) Bicarbonate requirement for the water-oxidizing complex of Photosystem II. Biochim Biophys Acta 1503: 187-196

Mende D and Wiessner W (1985) Bicarbonate in vivo requirement of Photosystem II in the green alga Chlamydobotrys stellata. J Plant Physiol 118: 259-266

Metzner H and Fischer K (1969) Becquerel effect and Hill reaction in model systems. Progr Photosynth Res II: 1027-1031

Michel H and Deisenhofer J (1988) Relevance of the photosynthetic reaction center from purple bacteria to the structure of Photosystem II. Biochemistry 27: 1-7

Nugent JHA, Corrie AR, Demetriou C, Evans MCW and Lockett CJ (1988) Bicarbonate binding and the properties of Photosystem II electron acceptors. FEBS Lett 235: 71-75

Petrouleas V, Deligiannakis Y and Diner BA (1994) Binding of carboxylate anions at the non-heme Fe(II) of PS II. Competition 
with bicarbonate and effects on the $\mathrm{Q}_{\mathrm{A}} / \mathrm{Q}_{\mathrm{B}}$ electron transfer rate. Biochim Biophys Acta 1188: 271-277

Robinson HH, Eaton-Rye JJ, van Rensen JJS and Govindjee (1984) The effects of bicarbonate depletion and formate incubation on the kinetics of oxidation-reduction reactions of the Photosystem II quinone acceptor complex. Z Naturforsch 39c: 382-385

Semin BK, Loviagina ER, Aleksandrov AY, Kaurov YN and Novakova AA (1990) Effect of formate on Mössbauer parameters of the non-heme iron of PS II particles of cyanobacteria. FEBS Lett 270: 184-186

Senebier J (1782) Mémoires physico-chimiques sur l'influence de la lumière solaire pour modifier les êtres de trois règnes, surtout ceux du règne végétal, 3 vols. Chirol, Geneva

Shopes RH, Blubaugh DJ, Wraight CA and Govindjee (1989) Absence of a bicarbonate-depletion effect in electron transfer between quinones in chromatophores and reaction centers of Rhodobacter sphaeroides. Biochim Biophys Acta 974: 114-118

Snel JFH and van Rensen JJS (1983) Kinetics of the reactivation of the Hill reaction in $\mathrm{CO}_{2}$-depleted chloroplasts by addition of bicarbonate in the absence and in the presence of herbicides. Physiol Plant 57: 422-427

Snel JFH and van Rensen JJS (1984) Reevaluation of the role of bicarbonate and formate in the regulation of photosynthetic electron flow in broken chloroplasts. Plant Physiol 75: 146-150

Stemler AJ (1980) Inhibition of Photosystem II by formate: possible evidence for a direct role of bicarbonate in photosynthetic oxygen evolution. Biochim Biophys Acta 593: 103-112

Stemler AJ (1982) The functional role of bicarbonate in photosynthetic light reaction II. In: Govindjee (ed) Photosynthesis, Vol II, Development, Carbon Metabolism and Plant Productivity, pp 513-539. Academic Press, New York

Stemler A and Govindjee (1973) Bicarbonate ion as a critical factor in photosynthetic oxygen evolution. Plant Physiol 52: 119-123

Stemler A and Murphy J (1983) Determination of the binding constant of $\mathrm{H}^{14} \mathrm{CO}_{3}{ }^{-}$to the Photosystem II complex in maize chloroplasts: effects of inhibitors and light. Photochem Photobiol 38: 701-707

van Rensen JJS and Vermaas WFJ (1981) Action of bicarbonate and Photosystem II inhibiting herbicides on electron transport in pea grana and in thylakoids of a blue-green alga. Physiol Plant 51: 106-110 van Rensen JJS, Tonk WJM and De Bruijn SM (1988) Involvement of bicarbonate in the protonation of the secondary quinone electron acceptor of Photosystem II via the non-haem iron of the quinone-iron acceptor complex. FEBS Lett 226: 347-351

van Rensen JJS, Xu C and Govindjee (1999) Role of bicarbonate in Photosystem II, the water-plastoquinone oxido-reductase of plant photosynthesis. Physiol Plant 105: 585-592

Vermaas WFJ and Rutherford AW (1984) EPR measurements on the effect of bicarbonate and triazine resistance on the acceptor side of Photosystem II. FEBS Lett 175: 243-248

Warburg O and Krippahl G (1958) Hill-Reaktionen. Z Naturforsch 13b: $509-514$

Warburg O (1964) Prefatory chapter. Annu Rev Biochem 33: 1-18

Wydrzynski T and Govindjee (1975) A new site of bicarbonate effect in Photosystem II of photosynthesis; evidence from chlorophyll fluorescence transients in spinach chloroplasts. Biochim Biophys Acta 387: 403-408

Xiong J, Subramaniam S and Govindjee (1996) Modeling of the D1/D2 proteins and cofactors of the Photosystem II reaction center: Implications for herbicide and bicarbonate binding. Protein Sci 5: 2054-2073

Xiong J, Minagawa J, Crofts A and Govindjee (1998a) Loss of inhibition by formate in newly constructed Photosystem II D1 mutants, D1-R257E and D1-R257M, of Chlamydomonas reinhardtii. Biochim Biophys Acta 1365: 473-491

Xiong J, Subramaniam S and Govindjee (1998b) A knowledgebased three dimensional model of the Photosystem II reaction center of Chlamydomonas reinhardtii. Photosynth Res 56: 229254

Xu C, Taoka S, Crofts, AR and Govindjee (1991) Kinetic characteristics of formate/formic acid binding at the plastoquinone reductase site in spinach thylakoids. Biochim Biophys Acta 1098: 32-40

Zouni A, Witt HT, Kern J, Fromme P, Krauss N, Saenger W and Orth P (2001) Crystal structure of Photosystem II from Synechococcus elongatus at $3 \AA$ A resolution. Nature 409:739-743 